\title{
Efficacy of Sublingual Use of Ketorolac Tromethamine in Reducing Pain During Treatment with Laser Photocoagulation in Patients with Diabetic Retinopathy Double Blind, Randomized, Sham-Controlled Study
}

Luiz Guilherme Azevedo de Freitas ${ }^{1 *}$, Roberta Albuquerque de Azevedo Paiva ${ }^{2}$, Thais Maria Pinheiro Callou ${ }^{3}$, Danielle de Albuquerque Carrera Araújo ${ }^{4}$, Clovis Arcoverde de Freitas Neto ${ }^{5}$, Tania Cursino de Menezes Couceiro ${ }^{6}$, Theophilo José de Freitas Neto ${ }^{7}$ and Marcos Pereira de Ávila ${ }^{8}$

${ }^{1}$ Department of Retina and Vitreous of the Hospital de Olhos Santa Luzia, Recife - PE - Brazil

${ }^{2}$ Physician, Instituto de Olhos Clóvis Paiva, Recife (PE), Brazil

${ }^{3}$ Fellowship in Refractive Surgery of the Universidade de São Paulo, São Paulo - Brazil

${ }^{4}$ Physician, Hospital de Olhos Santa Luzia/Santa Lucia Foundation, Switzerland

${ }^{5}$ Department of Retina and Vitreous of the Hospital de Olhos Santa Luzia, Recife - PE - Brazil

and Surgery Institution, Cambridge-MA

${ }^{6}$ Master of Neuropsychiatry and Behavioral Science UFPE - Brazil

${ }^{7}$ Head of the Retina Department of the Hospital de Olhos Santa Luzia/ Santa Lucia Foundation, Brazil

${ }^{8}$ Full Professor of Ophthalmology, Head of the Retina Department UFG/CBV/CBCO, Brazil

"Corresponding author: Luiz Guilherme Freitas, MD, Ophthalmologist and Retina and Vitreous specialist, Hospital de Olhos Santa Luzia/ Funda'c ao Santa Luzia, Road Pipeline 909, Eye Hospital Santa Luzia, PE Brazil, Tel: 558197354140; E-mail: luizgfreitas@gmail.com

Received date: Jul 29, 2014, Accepted date: Oct 21, 2014, Published date: Oct 23, 2014

Copyright: ( 2014 Freitas LG, et al. This is an open-access article distributed under the terms of the Creative Commons Attribution License, which permits unrestricted use, distribution, and reproduction in any medium, provided the original author and source are credited.

\section{Abstract}

Objective: To evaluate the analgesic effect of sublingual ketorolac tromethamine during argon laser photocoagulation in patients with diabetic retinopathy.

Methods: A double blind, randomized, sham - controlled study, was conducted in 60 patients with diabetic retinopathy, referred for argon laser panretinal photocoagulation (PRP). For the evaluation of pain intensity, a numerical scale from zero to ten was used. The trial sample was divided into two groups. Group 1 consisted of 27 patients who used one $10 \mathrm{mg}$ tablet of ketorolac tromethamine and group 2 comprised of 33 patients who used a sham, both with the same method of administration, 30 minutes before application of the laser.

Results: Of the 27 patients in Group 1, $20(74 \%)$ felt pain in the first stage, $5(19 \%)$ experienced pain in the second stage and $2(7 \%)$ felt no pain at any time. Of the 33 patients in Group 2, $27(82 \%)$ felt pain in the first stage, $3(9 \%)$ experienced pain in the second stage and $3(9 \%)$ felt no pain at any time. There was no statistically significant difference between the groups ( $p=0.65$ and 0.33 )

Conclusion: Ketorolac tromethamine was not able to reduce pain during panretinal photocoagulation in patients with proliferative diabetic retinopathy.

Keywords Laser photocoagulation; Pain management; Ketorolac tromethamine; Diabetic retinopathy

\section{Introduction}

Diabetic retinopathy (DR) is an ocular manifestation of diabetes and is a leading cause of blindness in people between the ages of 20 and 74 in the USA [1]. The proliferative form of the disease is the most feared by their visual complications, due to its ocular manifestations such as retinal ischemia, which leads to a retinal neovascularization.

It is estimated that in eyes with untreated proliferative DR, the rate of progression to blindness is $50 \%$ at 5 years [2-4] and that about $80 \%$ of diabetics with over 25 years of the disease will have some sign of retinopathy $[5,6]$. One of the treatments performed for the proliferative form of the disease is argon laser photocoagulation. A study such as the Retinopathy Diabetic Study (RDS) proved that panretinal photocoagulation (PRP) is effective and reduces severe visual loss in patients with this disease [7]. It is known that when the patient is subjected to photocoagulation the feeling of pain can range from mild to severe intensity during the procedure [8]. Pain during PRP is thought to result from photocoagulation the ciliary nerves running in the suprachoroidal space [9]. In order to reduce pain, analgesia can be performed with a injection of anesthetic, retrobulbar, peribulbar, or subtenonian, however, all these procedures have risks of complications, limiting their applicability. Oral analgesics may be an alternative to reduce the discomfort felt by the patient during a session of laser therapy.

Ketorolac tromethamine is a nonsteroidal anti-inflammatory potent analgesic, available in sublingual form and is a drug indicated for short-term treatment of acute moderate to severe pain.

The purpose of this study is to evaluate the analgesic effect of sublingual ketorolac tromethamine during argon laser photocoagulation in patients with diabetic retinopathy. 
Citation: Freitas LG, Paiva RAA, Callou TMP, Araújo DAC, Neto CAF, et al. (2014) Efficacy of Sublingual Use of Ketorolac Tromethamine in Reducing Pain During Treatment with Laser Photocoagulation in Patients with Diabetic Retinopathy Double Blind, Randomized, ShamControlled Study. J Clin Exp Ophthalmol 5: 364. doi:10.4172/2155-9570.1000364

Page 2 of 3

\section{Materials and Methods}

The Ethics Committee of the Agamemnon Magalhães Medical Research Hospital approved this study. A double-blind, randomized, sham-controlled study, was conducted, at the Santa Luzia Hospital/ Santa Luzia Foundation, in the city of Recife (HOSL/FSL), from March 2012 to February 2013, where 60 patients suffering from diabetic retinopathy were examined, referred from the outpatient retinal clinic of Santa Luzia Foundation for PRP laser. The patients had already done a clinical history and complete examination with binocular indirect ophthalmoscopy under mydriasis.

A research questionnaire was used which contained: Identification, sex, type of treatment for diabetes mellitus (oral medication and/or insulin therapy), prior treatment with laser photocoagulation for diabetic retinopathy.

Unidimensional pain scales were used for assessment of pain: Numerical Rating Scale (NRS) and the Faces Pain Scale (FPS) with 6 faces. The NRS evaluate the pain on a scale of 0 to 10 , or a scale from 0 to 5 categories with 0 representing no pain and 10 indicating worst pain. The FPS evaluates the pain according to which face drawn represents, the expression of happiness rating corresponds to no pain and the expression of sadness corresponds to the maximum pain $[10,11]$.

Inclusion criteria were: over 18 years of age; a consent form freely signed by the patient or his guardian; diagnosed with diabetic retinopathy by clinical and/or additional eye exams; being monitored at the Retinal Department of the Santa Luzia Foundation.

Exclusion criteria were: corneal opacities or cataracts that prevented adequate visualization of the retina; retinal disease other than diabetic retinopathy; and refusal by the patient to participate in the study.

The study sample was divided into two groups. Group 1 consisted of 27 patients who used one $10 \mathrm{mg}$ tablet of sublingual ketorolac tromethamine 30 minutes before laser application. Group 2 consisted of 33 patients who used a sham (pill manufactured with a corn starch base), with the same route of administration, $30 \mathrm{~min}$ before laser application. Patients were divided into the two groups randomly. In each patient just only one eye could be treated (Figure 1).

The pupillary dilatation was performed using $1 \%$ tropicamide (Mydriacyl; Alcon Inc.) and phenylephrine hydrochloride 10\% (Allergan).

The photocoagulation was performed using an argon laser (VISULAS 532s, Zeiss): an average of 500 pulses with 200 micron spot size, and pulse duration of 0.2 seconds were performed, maximum treatment time of 30 minutes and on average 15 minutes.

Immediately after the session, patients were questioned about the presence and intensity of pain felt during the procedure. Pain assessment was carried out using NRS and FPS scales. Fifteen minutes after the procedure, patients were again asked about the pain (Figure 1). The questions were taken immediately after and 15 minutes after photocoagulation so that acute pain was evaluated.

The same ophthalmologist always performed the photocoagulation procedure and another professional performed the pain assessment, on both occasions, in order to avoid technical and collection errors.

The volunteers were responsible for the randomization of patients, the distribution of the drug and sham as well as the application of pain assessment scales through.

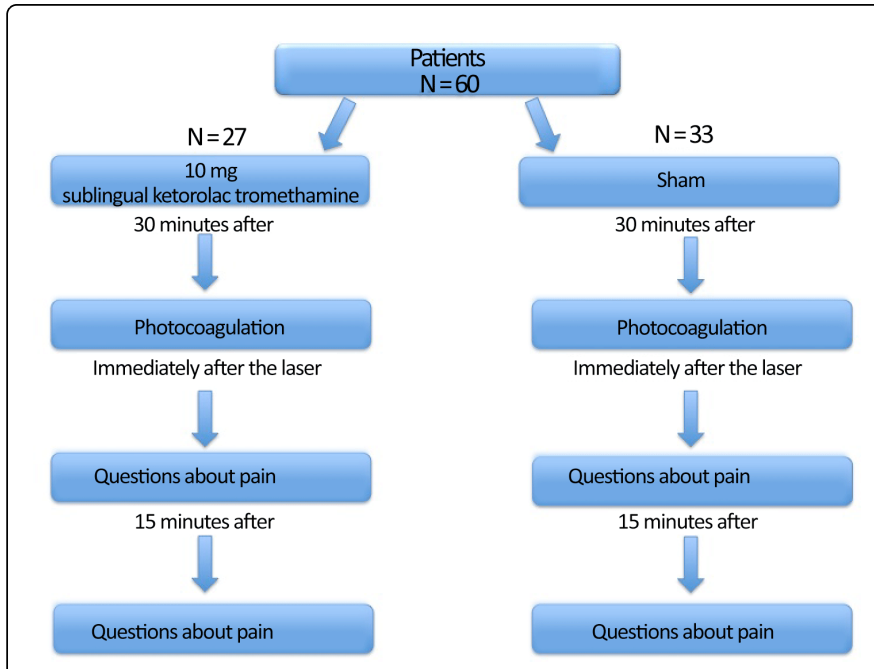

Figure 1: Flowchart of Study Methodology.

\section{Statistical analysis}

The data was evaluated using Excel through the MYSQL database (Microsoft Corp., Red-mond, WA). Statistical analysis was performed using STATA/SE 12.0 for Windows, using Two-sample Wilcoxon rank-sum (Mann-Whitney) test for comparisons between groups. We considered $\mathrm{p}=0.05$ to be significant.

\section{Results}

Were studied 60 patients (60 eyes) with a mean age of 58 years. Of the patients, $26(43 \%)$ were male, $46(77 \%)$ were insulin therapy dependent and 42 (70\%) had already undergone laser photocoagulation on another occasion. Within the sample studied, in Group 1, 27 patients (45\%) used ketorolac tromethamine for evaluation of analgesia and in Group 2, 33 patients (55\%) used the sham.

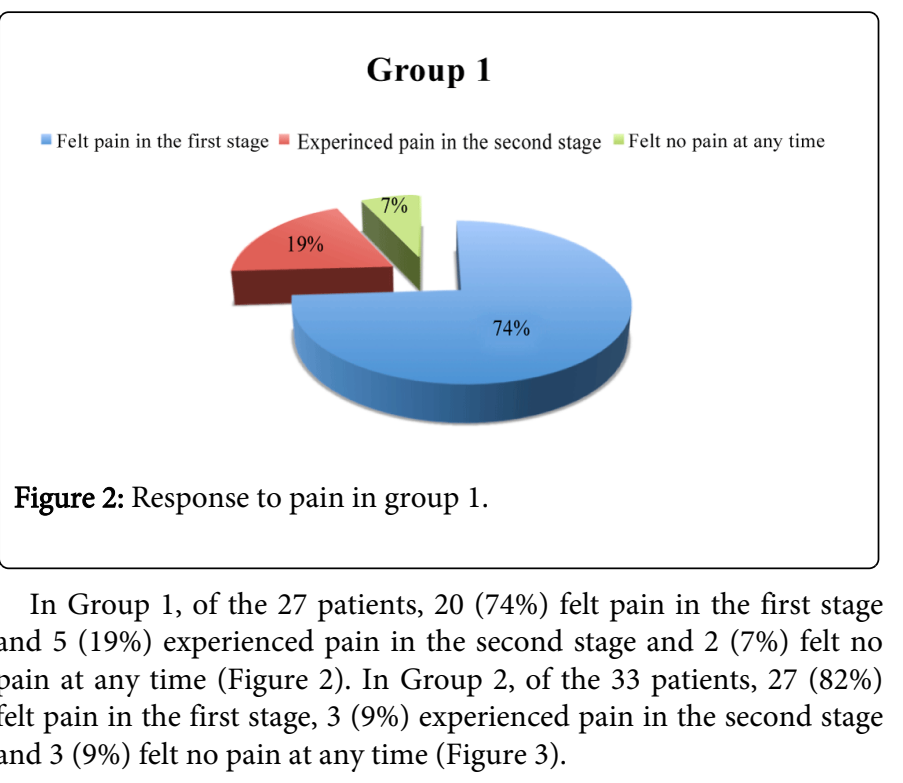


Citation: Freitas LG, Paiva RAA, Callou TMP, Araújo DAC, Neto CAF, et al. (2014) Efficacy of Sublingual Use of Ketorolac Tromethamine in Reducing Pain During Treatment with Laser Photocoagulation in Patients with Diabetic Retinopathy Double Blind, Randomized, ShamControlled Study. J Clin Exp Ophthalmol 5: 364. doi:10.4172/2155-9570.1000364

Page 3 of 3

There was no statistically significant difference between the groups $(\mathrm{p}=0.65$ and 0.33$)$.

\section{Group 2}

$=$ Felt pain in the first stage $\quad$ = Experinced pain in the second stage $=$ Felt no pain at any time

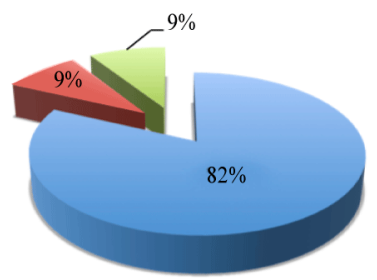

Figure 3: Response to pain in group 2.

\section{Discussion}

This study showed no difference of pain reduction in patients who received the sham and ketorolac tromethamine after laser photocoagulation. This result corroborates previous published studies related to the evaluation of pain after laser therapy [9].

The literature shows different ways of trying to reduce pain in patients undergoing laser therapy. The study by Techa and colleagues concluded that a subconjunctival injection of $2 \%$ lidocaine significantly reduces the incidence of pain [12].

Not all methods of reducing the pain were effective. Studies have concluded that both the intramuscular injection of ketorolac tromethamine and the use of diazepam, mefenamic acid and acetaminophen (alone or in combination with each other) are not effective in reducing pain perception. Only peribulbar block was effective in reducing pain for this procedure [13]. However, one should take into consideration the risk/benefit of this technique. The risks posed by these types of analgesia such as perforation of the eye, retrobulbar hemorrhage, traumatic optic neuropathy, central nervous system as well as cardiorespiratory depression have been reported complications of this form of anesthesia [13]. In addition to the risks of retrobulbar anesthesia, it induces akinesia making it a disadvantage when you need to direct the patient's eye movements during treatment.

\section{Conclusion}

Ketorolac tromethamine was not able to reduce pain during argon laser photocoagulation in patients with proliferative diabetic retinopathy.
The study has some limitations. We considered patients who had undergone photocoagulation and this can interfere somehow, in pain assessment. Studies with patients without prior laser treatments should be performed to confirm the results with greater fidelity.

\section{References}

1. Klein R, Klein BEK (2000) Epidemiology of Eye Disease in Diabetes. Flynn Jr HW, Smiddy WE (Eds). Diabetes and Ocular Disease: Past, Present, and Future Therapies. The Foundation of the American Academy of Ophthalmology pp-19-61.

2. Beetham WP (1963) Visual Prognosis of Proliferating Diabetic Retinopathy. Br J Ophthalmol 47: 611-619.

3. Caird FI, Burditt AF, Draper GJ (1968) Diabetic retinopathy. A further study of prognosis for vision. Diabetes 17: 121-123.

4. Deckert T, Simonsen SE, Poulsen JE (1967) Prognosis of proliferative retinopathy in juvenile diabetics. Diabetes 16: 728-733.

5. Taleb AC, Ávila M, Almeida R, Bicas H (2007) As Condições de Saúde Ocular no Brasil-2007. 1a Edição. Conselho Brasileiro de Oftalmologia. São Paulo, pág-20-21.

6. Taleb AC, Ávila M, Moreira H (2009) As Condições de Saúde Ocular no Brasil-2009. 1a Edição. Conselho Brasileiro de Oftalmologia. São Paulo.

7. The Diabetic Retinopathy Study Research Group (1981) Photocoagulation treatment of proliferative diabetic retinopathy. Clinical application of Diabetic Retinopathy Study (DRS) findings, DRS Report Number 8. The Diabetic Retinopathy Study Research Group. Ophthalmology 88: 583-600.

8. Tamai M, Mizuno K (1984) Distribution of intra- and extraocular pain induced by argon laser photocoagulation. Tohoku J Exp Med 142: $427-435$.

9. Wu WC, Hsu KH, Chen TL, Hwang YS, Lin KK, et al. (2006) Interventions for relieving pain associated with panretinal photocoagulation: a prospective randomized trial. Eye (Lond) 20: 712-719.

10. Pereira LV, Sousa FA (1998) [Measurement and assessment of postoperative pain: a short review]. Rev Lat Am Enfermagem 6: 77-84.

11. Williamson A, Hoggart B (2005) Pain: a review of three commonly used pain rating scales. J Clin Nurs 14: 798-804.

12. Tesha PE, Giavedoni LR, Berger AR, Altomare F, Chow DR, et al. (2010) Subconjunctival lidocaine before laser treatment: a randomized trial. Ophthalmology 117: 1810-1814.

13. Kallio H, Paloheimo M, Maunuksela EL (2000) Haemorrhage and risk factors associated with retrobulbar/peribulbar block: a prospective study in 1383 patients. Br J Anaesth 85: 708-711. 